\title{
The End of Life Choice Act: a proposed implementation and research agenda
}

\author{
Jessica E Young, Janine Winters, Jeanne Snelling, Ben P White, \\ Colin Gavaghan, Andrew Geddis, Richard Egan
}

\begin{abstract}
AIM: This article outlines the End of Life Choice Act 2019. It highlights some of the key implementation issues to ensure the system operates safely and equitably after the Act comes into force. It also identifies priorities for research to ensure issues are detected and provision of assisted dying (AD) is monitored.

METHOD: We reviewed the End of Life Choice Act, assisted dying implementation literature and governmental reports.

RESULTS: Effective system implementation depends on infrastructure, oversight and funding. In terms of service provision, we make recommendations about training for all health practitioners and providing practitioners; the nuances of discussing the "wish to hasten death"; conscientious objection; cultural safety for Māori; and minimising the complexity of delivering assisted dying practice. Structured research is needed to understand how the assisted dying system is operating.

CONCLUSION: This article contributes by identifying core issues for practitioners, patients and policymakers. Implementation is an ongoing process that continues after the Act starts. Data are required to know whether access is equitable, who is choosing to make use of the law, whether providers are well informed and whether the safeguards are working as intended. The implications of how the Act is implemented are significant for patients, whānau, health professionals and society.
\end{abstract}

$\mathrm{T}$ he purpose of this article is to examine the critical challenges for implementing the End of Life Choice Act 2019 (henceforth the EoLC Act or the Act) in New Zealand and to identify key future research needs. The EoLC Act, passed by Parliament (69-51) in 2019 and ratified via public referendum at the 2020 election, comes into force on 7 November 2021. The Act legalises assisted dying $(\mathrm{AD})$ for adults who are assessed by at least two medical practitioners as meeting specified criteria. The Act stipulates many procedural steps for access. The implementation of AD will create various challenges for a range of health practitioners, and indeed for the health system as a whole. ${ }^{1}$ Health practitioners will need written guidelines for responding to requests for $\mathrm{AD}$, procedures for providing $\mathrm{AD}$ and support for the clinical dilemmas that will inevitably arise, some of which are discussed below..$^{2-6}$ Patients and families will also need significant support; 7,8 their concerns are not the focus of this article. This article outlines the Act, highlights key implementation issues and identifies priorities for research. Although several Australian jurisdictions designated an 18-month period for implementation, ${ }^{9}$ the EoLC Act comes into force just 12 months after announcement of the referendum's result. Thus, the implementation issues and formation of an implementation research agenda are matters of some urgency.

\section{Overview of the Act}

The aims of the EoLC Act are to "a) to give persons who have a terminal illness and who meet certain criteria the option of lawfully requesting medical assistance to end their lives; and b) to establish a lawful process for assisting eligible persons who exercise that option" (Section 3). ${ }^{10}$ To be eligible for assisted dying under the Act, two doctors must agree that a person meets, and continues to meet throughout the appli- 
cation process, all of the criteria set out in sections 5 and 6 of the Act. ${ }^{11}$ The person must: be aged 18 years or older; be a citizen or permanent resident of New Zealand; have a terminal illness that is likely to end their life within six months; be in an advanced state of irreversible decline in physical capability; and be experiencing unbearable suffering that cannot be relieved in a way that is acceptable to them. Further, in an attempt to protect people who may be vulnerable, the Act excludes people whose sole reason for requesting $\mathrm{AD}$ is because of advanced age or having a mental disorder or mental illness, or a disability of any kind. However, if people with such conditions also meet the eligibility criteria, they may still access AD. Notably, persons suffering from grievous and irremediable medical conditions are not eligible for $\mathrm{AD}$ under the Act (as they were under the initial End of Life Choice Bill).

The Act also requires that the requesting person is competent to make an informed decision about $\mathrm{AD}$, which is defined as the capacity to "understand information about the nature of assisted dying that is relevant," to retain that information and to use or weigh that information to help them decide and communicate (including non-verbally) a decision..$^{10}$ If either the "attending medical practitioner" (AMP, the person's medical practitioner for $\mathrm{AD}$ ) or the "independent medical practitioner," who provides a second opinion on eligibility, are not satisfied of the person's competence, then a psychiatrist must assess the person. Different from other medical decisions, there is no presumption of competence for the purposes of the EoLC Act (the Act introduces a new clause (5A) into the Code of Health and Disability Services Consumers' Rights (the Code) stating that Rights 7(2)-(5) of the Code (which encompasses the presumption of capacity) is overridden by EoLC Act Section 6). The person must have capacity at the time of application and assessment for $\mathrm{AD}$ and at the time of receiving the lethal medication. They cannot sign an advance directive for AD (Section 33), and no welfare guardian has any power to make decisions or take actions under the Act (Section 34).

The Act specifies that, after being assessed as eligible for $\mathrm{AD}$, the person and the provider must set a date and time for provision of the lethal medication. The eligible person may choose to either self-administer the medication by ingestion or intravenously, or have a doctor or nurse practitioner administer it by injection or through a tube. The eligible person may choose not to receive the medication, or may elect a different date up to six months after the initial date.

When a person raises the issue of $\mathrm{AD}$, the Act prescribes procedural steps, primarily outlined in Section 11, intended as safeguards. See Figure 1 for an overview of the required steps. The AMP must "ensure" the person requesting $\mathrm{AD}$ understands alternative options for end-of-life care, and must give the person information regarding their prognosis and that $\mathrm{AD}$ is irreversible. The AMP must "do their best to ensure" that a person's expressed wish to access AD is made "free from pressure" from any others by conferring with other health practitioners, by discussing with family (if authorised by the person) and by discussing the choice with the person over time at intervals determined by their disease trajectory, including via telephone or electronic communication. The AMP must encourage, but cannot compel, the person to talk to others such as family, friends or counsellors. At every step of the process, the AMP or nurse practitioner (who is permitted to administer the medication) must "ensure" that the person knows they can change their mind at any time before the medication is given. If at any point the AMP or nurse practitioner suspects on reasonable grounds that a person is being pressured about their decision, the AMP must stop the process immediately, and inform the Registrar (a regulator at the New Zealand Ministry of Health) for AD.

\section{Implementing infrastructure}

The Ministry of Health (the Ministry) is responsible for administering the Act and is in the early stages of establishing a programme for implementation. The Ministry has established a work programme and milestones, which can be found on the EoLC Act webpage. ${ }^{12}$ This currently shows that governance groups and statutory bodies are being established. 
Figure 1: Simplified assisted dying application process.

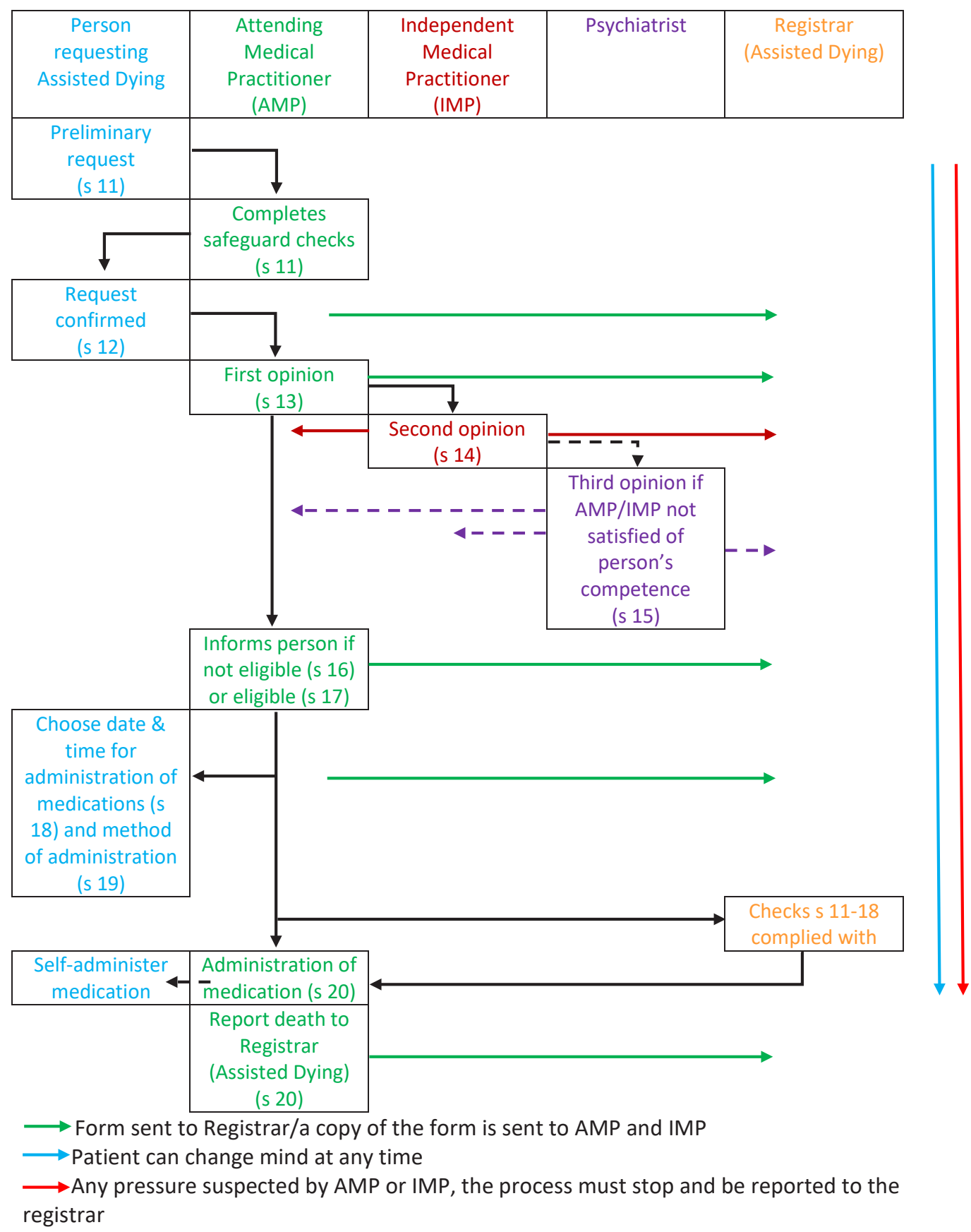




\section{Oversight}

Oversight under the Act is the responsibility of three new entities: the End of Life Review Committee, the Support and Consultation for End of Life in New Zealand (SCENZ) Group and the Registrar (Assisted Dying). The Review Committee is comprised of a medical ethicist and two health practitioners, including one who practices in end-of-life care. The Review Committee is responsible for reviewing each assisted death report for compliance with the Act's requirements.

The Act provides that the Director-General of Health must establish the SCENZ Group and appoint members who he considers, collectively, have knowledge and understanding to enable it to discharge its statutory functions..$^{13}$ The SCENZ Group is responsible for maintaining a list of health practitioners (medical practitioners, psychiatrists, pharmacists and nurse practitioners) who are willing to be involved in the process. Those on this list may act as the attending medical practitioner if a patient's usual practitioner declines to participate or conscientiously objects, and they may also act as the independent medical practitioner providing the second opinion. The SCENZ Group is also responsible for developing standards of care, and advising on medical and legal procedures in relation to the administration of medications used in AD. Processes will need to be developed in regards to composition and dose of medication as well as logistics including prescription, obtaining, handling, storage and disposal of medication if unused. ${ }^{1}$

The functions of the Registrar include maintaining a register of $\mathrm{AD}$ forms, reviewing the relevant forms that must be lodged at each step in the process, reporting annually to the Ministry and receiving complaints about health practitioners. Medication may only be administered if the Registrar notifies the AMP that all of the relevant processes have been complied with. The timing of the Registrar's review, checking that all procedural steps of the Act have been completed, will be important for patients close to the end of life..$^{14}$ Early research about Victoria's AD system suggests its prospective oversight and approval process has caused delays for otherwise eligible patients wishing to access AD. ${ }^{15}$

\section{Funding and resource allocation}

Funding for service delivery has been approved and provider training at the time of publication is yet to be determined. The multiple consultations, and in particular the statutory requirement for the attending health practitioner to be available nearby until death, commands a significant commitment of providers' time. Additional funding for palliative care is also needed. Further factors complicating funding is competition for scarce resources in the New Zealand health system, such as psychiatrist evaluations.

\section{Implementing the law: service provision}

Translating legislation into clinical practice, especially a new area of practice, is challenging for all people and services involved. ${ }^{1}$ The greatest complexity is in delivering services and the variability of the needs and actions of the stakeholders that include patients, families, direct providers, other healthcare practitioners, tangata whenua and wider society.

Lessons regarding regulatory, ethical, legal, social, financial and logistical challenges can be learned from overseas jurisdictions. ${ }^{9,16,17}$ Recommendations from this literature include: establishing working groups led by experts overseen by a dedicated implementation taskforce to ensure alignment across groups; creating models of care that illustrate varying levels of organisational participation in providing $\mathrm{AD}$; step-by-step clinical guidance; mentoring and training for providers; accurate consumer information; a centralised medication service; transparent data and government-funded independent evaluation research; and regular communication and meetings between Ministry and relevant organisations/stakeholders. . $, 5,9,14,16,18,19$ Designated local contacts from the health services could be established as a productive conduit for information between the Ministry and health services. ${ }^{9}$ This could help ensure effective implementation at the coalface and also provide feedback about feasibility of different aspects of the process in practice. ${ }^{9}$

It is not possible to address all implementation challenges in a single article. However, we address the following key issues that are 
critical for the implementation of the EoLC Act: training, how to have conversations about $\mathrm{AD}$, conscientious objection, cultural safety and delivery of AD in practice.

\section{Training for all healthcare practitioners}

Although the Act contains no formal requirement for training for health practitioners, this does not preclude it, and safe and successful implementation of the Act requires it. This training needs to include training for nurses and other healthcare workers who will be co-providing care for people requesting, or undergoing, $\mathrm{AD} .^{20}$ Training can be divided into two broad categories. The first is training for all healthcare workers. It includes information about the law, obligations under the law, conscientious objection, navigating $\mathrm{AD}$ discussions and supporting patients, families and colleagues (Table 1). The second broad category is training for doctors and nurses who choose to be directly involved in delivery of AD.

\section{Training direct providers}

Training must clarify the procedures for practical matters not addressed in statute. ${ }^{21}$ In Australia, mandatory training for doctors who wish to assess eligibility is delivered via a module-based online programme that encompasses the law, doctors' roles, duties and protections, as well as relevant clinical skills. ${ }^{21}$ Clear guidance will be needed to assist providers to determine whether a person is eligible or not. In particular, guidance will be needed to interpret the scope of the core criteria that a person suffers a "terminal illness likely to end the person's life within 6 months," and is an "advanced state of irreversible decline in physical capability” and experiences "unbearable suffering." Training could also usefully cover identifying coercion, navigating competence assessments (including when a psychiatrist should be consulted) and identifying/addressing troublesome treatable symptoms (including when to refer

Table 1: Training for all healthcare workforce for End of Life Choice Act of 2019.

\begin{tabular}{|c|c|}
\hline & Training about AD and EoLC Act for all healthcare providers \\
\hline General & 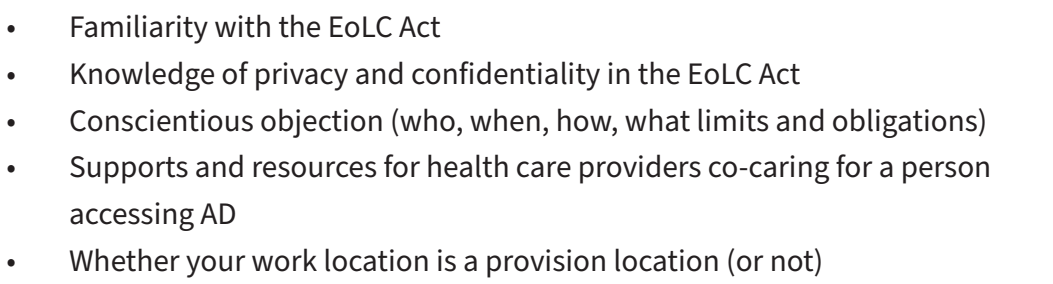 \\
\hline $\begin{array}{l}\text { Relating and com- } \\
\text { municating }\end{array}$ & 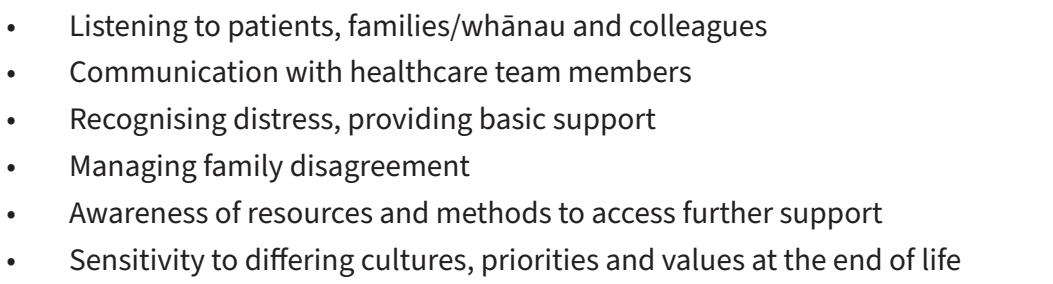 \\
\hline $\begin{array}{l}\text { Initial informal } \\
\text { patient request } \\
\text { (made to a } \\
\text { non-provider) }\end{array}$ & 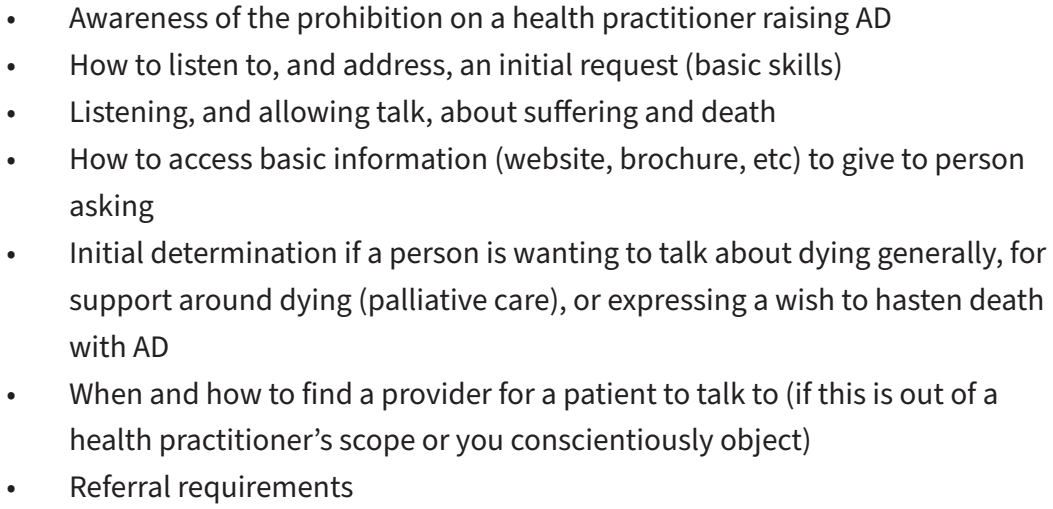 \\
\hline
\end{tabular}


to palliative care specialists). Standardising doctors' baseline knowledge to enhance their skills is important for consistency of decision-making. ${ }^{21}$ Table 2 presents a list of competencies, considerations and training areas for providers in New Zealand based on the unique elements in the EoLC Act.

Training also extends past the initial period. Developing mentorship and peer groups would facilitate the exchange of knowledge as experience with the procedure increases. In some jurisdictions, communities of AD practitioners emerged to support each other and developed their own standards (eg, Canadian Association of MAID Assessors and Providers).

\section{Navigating assisted dying discussions}

A vital part of implementation and training is how to discuss AD with patients, including prior to a formal request for $\mathrm{AD}$ being made. Talking about AD raises issues such as when can it be discussed with a patient, what constitutes a request and whether a patient raising the topic of $\mathrm{AD}$ is the same as a request for hastened death. There is also the issue of what communication about $\mathrm{AD}$ that a health practitioner is obliged to provide when the provider personally objects to $\mathrm{AD}$, which is discussed in the next section.

Section 10 of the Act states that no health practitioner, not only those eligible to provide $\mathrm{AD}$, may initiate any $\mathrm{AD}$ discussion or make any suggestions in substance that a person choose to receive $\mathrm{AD}$. To do so is in breach of the Act. Such a breach may lead to a complaint to the Health and Disability Commissioner, and in cases of serious breaches, the health practitioner may be subject to disciplinary proceedings under the Health Practitioners Competence Assurance Act 2003 (Section 38(2)). Further, a wilful failure to comply with any requirement of the Act is an offence (Section 39(1)) (liable on conviction to prison up to three months or a fine of $\$ 10,000$ ).

The Act adopts this prohibition from the Victorian legislation. Early analysis of the operation of the Victorian AD system confirms this prohibition has been problematic in practice., 3,622 "If patients are unaware of the prohibition on doctors raising $\mathrm{VAD}$, they may assume that VAD is not an available option for them or that they are not eligible."2 The public will need to be informed that, for the $\mathrm{AD}$ process to be initiated, the patient needs to make an explicit request for AD. Patients will require considerable social and cultural capital, as well as health literacy, to know or find out about $\mathrm{AD}$ and to request it in a manner that is considered credible and sufficient by the receiver. ${ }^{23,24}$

Although the intention of ensuring no one is coerced and avoiding "suggestibility" are important, the prohibition on initiating the first $\mathrm{AD}$ conversation becomes problematic in practice, ${ }^{6}$ particularly in determining what constitutes a request. Another concern is that practitioners may avoid any discussions for fear of repercussions. ${ }^{2}$ These are practical challenges that result in health practitioners being unclear about what they can say when a patient is in a contemplative stage of decision making. Implementation guidance must be clear on what constitutes a request for $\mathrm{AD}$ information (and what does not) to ensure health practitioners feel confident in practising within the bounds of law in a difficult new area of practice. Guidance is also needed on how to respond to an ambiguous request.

Even once it is clear a request for $\mathrm{AD}$ information is being made, practitioners should be aware that an expression of a wish to hasten death is not always a literal request. ${ }^{25}$ For some people it is an expression of despair about one's current circumstances, a vehicle to talk about dying, an expression of unmet need or a coping strategy for anticipated agony. ${ }^{26}$ Others will go through the approval process to have the option available to them if they need it. However, for others the wish to hasten death is enduring. Training should cover the nuanced reasons, functions and meanings of patients raising AD with them. Health professionals ideally should be willing to openly discuss dying, assisted or otherwise. Norwood reports that most "euthanasia talk" does not lead to $\mathrm{AD}$; like talking about suicide, it serves a palliative function and may prevent most assisted deaths from occurring. ${ }^{27}$ Conscientious objection should not interfere with open discussion of a patient's views on the death and dying, including $\mathrm{AD}$. 
Table 2: Training and other considerations for providing doctors and administering nurse practitioners.

\begin{tabular}{|c|c|}
\hline & Training for providers of AD under the EoLC Act \\
\hline $\begin{array}{l}\text { Choosing to be a } \\
\text { Provider }\end{array}$ & $\begin{array}{l}\text { - What is required to become a provider } \\
\text { - What is required of a provider } \\
\text { inding advice/resources to determine whether AD is within scope of practice, } \\
\text { - Competency in communication and the elements of informed consent } \\
\text { - Ability to convey information about options, symptom management, pallia- } \\
\text { - tive care } \\
\text { - Basic knowledge of medical ethics regarding end-of-life care } \\
\text { - How to access more training } \\
\text { - What supports are available to providers } \\
\text { Reimbursement process }\end{array}$ \\
\hline $\begin{array}{l}\text { At initial informal } \\
\text { request }\end{array}$ & $\begin{array}{l}\text { - Advanced skills in the same areas from initial informal request in Table } 1 \\
\text { - } \quad \text { Assessing eligibility criteria and ineligible conditions (age, mental illness, disability) } \\
\text { - Expertise in differentiating a serious request for AD from request for more support, } \\
\text { symptom management or discussing fears about the future }\end{array}$ \\
\hline $\begin{array}{l}\text { At initial formal } \\
\text { patient request }\end{array}$ & $\begin{array}{l}\text { - } \text { Awareness of the prohibition on a health practitioner raising AD } \\
\text { - How to approach and address an initial request } \\
\text { - } \quad \text { How to access information (checklist) to provide to person } \\
\text { - } \quad \text { Referral requirements and methods } \\
\text { - } \quad \text { Knowledge of forms (and their purpose) completed at initial request and other } \\
\text { stages } \\
\text { Differentiate provider response options for differing clinical scenarios (eg, between } \\
\text { requests driven by long-standing values versus impulsive or momentary distress) }\end{array}$ \\
\hline $\begin{array}{l}\text { Assessment for } \\
\text { eligibility }\end{array}$ & $\begin{array}{l}\text { Prognostication } \\
\text { - } \quad \text { Familiarity with prognostication literature and resources } \\
\text { - } \quad \text { Familiarity with how to find and use New Zealand Hospice and Palliative Care } \\
\text { - } \quad \text { Referral Criteria for Adults } \\
\text { - } \quad \text { Coercion } \\
\text { - } \quad \text { How to evaluate and detect coercion, how to differentiate coercion, support and } \\
\text { - } \quad \text { Rersuasion } \\
\text { - } \quad \text { Privacy limitations of collecting information from other sources } \\
\text { - } \quad \text { How to address scenarios of unmet resource needs (symptom management, care- } \\
\text { Competency assessment } \\
\text { - } \quad \text { What standards and tools are recommended for routine use } \\
\text { - } \quad \text { Knowledge of strengths and weakness of different capacity assessment tools } \\
\text { - Which capacity assessment tools are available for special circumstances such as } \\
\text { Informed consent } \\
\text { - } \quad \text { Skilled in meeting elements of informed consent } \\
\text { - Documentation required, supporting documentation recommended } \\
\text { - Consider witnesses or recording for challenges after the fact } \\
\text { - Identifying and navigating difficulties with communication or learning differences }\end{array}$ \\
\hline
\end{tabular}


Table 2: Training and other considerations for providing doctors and administering nurse practitioners (continued).

\begin{tabular}{|c|c|}
\hline & Training for providers of AD under the EoLC Act \\
\hline $\begin{array}{l}\text { Between qual- } \\
\text { ification and } \\
\text { provision }\end{array}$ & $\begin{array}{l}\text { Clinical dilemmas (tricky situations)-identify and access available resources } \\
\text { - } \quad \text { Understand what the Registrar/SCENZ/Review Committee can provide } \\
\text { - } \quad \text { Understand when and how to get a legal opinion or clarification } \\
\text { - } \quad \text { Understand when and how to get expert clinical ethics consultation } \\
\text { Counselling, support, choreography, managing distress } \\
\text { - } \quad \text { Counselling families, managing dynamics } \\
\text { - } \quad \text { Communication with healthcare team members } \\
\text { - } \quad \text { Awareness of resources and methods to access (personal, team) supports } \\
\text { - } \quad \text { Responding to requests to reschedule forward or backwards } \\
\text { - } \quad \text { Responding to common changes in circumstances } \\
\text { - } \quad \text { Determining limitations on appropriate locations for procedures } \\
\text { - } \quad \text { Safety in acquiring, transporting and handling medications } \\
\text { - } \quad \text { Anticipating IV access and problems with IV access } \\
\text { - } \quad \text { Anticipating privacy concerns }\end{array}$ \\
\hline During provision & $\begin{array}{l}\text { - } \quad \text { Medication administration-how to use and side effects } \\
\text { - } \quad \text { Anticipating vomiting or problems with oral administration } \\
\text { - } \quad \text { Coordination of patient, family and staff on day of death } \\
\text { - } \quad \text { Guiding and counselling families (before, during and immediately after) } \\
\text { - } \quad \text { Managing boundaries and social media (recording devices, live streaming) } \\
\text { - } \quad \text { Familiarisation with provider personal safety } \\
\text { - } \quad \text { Role and strategies if other team members develop distress } \\
\text { - } \quad \text { How to proceed if patient the does not die within the expected time frame }\end{array}$ \\
\hline After provision & $\begin{array}{l}\text { - Technical aspects such as death certification, reporting death to Registrar, cap- } \\
\text { turing demographics and statistics being collected, privacy, and other required } \\
\text { documentation } \\
\text { - When, where and how the provider can get (funded) personal support } \\
\text { - Supporting families/whānau immediately after death: } \\
\text { - When families experience distress or ask questions in weeks or months after } \\
\text { death } \\
\text { - Differentiating grief from depression } \\
\text { - Recognising when to refer whānau for further support, grief vs depression } \\
\text { - Responding to, or de-escalating, angry family members } \\
\text { - Self-care for providers after involvement in AD } \\
\text { - Offences and protection for providers acting in accordance with the Act }\end{array}$ \\
\hline
\end{tabular}




\section{Conscientious objection}

Health practitioners (or organisations) with conscientious objection to $\mathrm{AD}$ are not compelled to participate (Section 8). ${ }^{28}$ However, a medical practitioner must inform the patient of their conscientious objection and tell the person they can contact the SCENZ Group who will help them find a provider. Organisations, particularly hospitals, hospices, general practices, aged care facilities and DHBs, need policies and procedures about how they will respond to enquiries about $\mathrm{AD}$ from patients, and how to accommodate the diverging views of staff and their willingness to participate in various aspects of AD. Institutional objections may have a significant impact on access to $\mathrm{AD}$ and working around objecting organisations may be a major implementation challenge. ${ }^{29}$

\section{Cultural safety}

Under Te Tiriti o Waitangi, Māori have a right to culturally safe care from providers. There is a diversity of views among Māori on $\mathrm{AD}^{30-32}$ Whānau are a crucial consideration for Māori regarding $\mathrm{AD}$, and for other cultures too. ${ }^{30}$ For some Māori, autonomy is not the only consideration in dying, because the dying person is not considered an isolated individual but inextricably connected to one's ancestors, living whānau and future generations. ${ }^{30}$ As the person is encouraged to discuss their $\mathrm{AD}$ decision with their loved ones, there is scope to include whānau in the decision-making process. End-of-life tikanga ("right" or "correct" traditional practices) and kawa (protocol) hold special significance and should be discussed by Māori requesting $\mathrm{AD}$ with their whānau (family) and hapū (subtribe). Health practitioners should be proactive in encouraging these conversations, while acknowledging the diversity among Māori. Given substantial evidence of conscious and unconscious bias that disadvantages Māori and issues of access to care and in health policy, ${ }^{33}$ providing culturally responsive care and equitable access to $\mathrm{AD}$ while at the same time safeguarding structurally disadvantaged populations is crucial. Consultation with Māori health organisations throughout the implementation process and beyond is recommended.

\section{Delivering assisted dying in practice}

$\mathrm{AD}$ provision for New Zealanders is complex and will require the coordination of multiple services and practitioners with varying levels of participation. Clear and accessible protocols and systems will be important so people requesting $\mathrm{AD}$ and their providers have information and forms readily available. This also assists in making compliance and data collection easier. ${ }^{1}$ There is a need for a consumer and provider information service that provides explanations in plain English and other languages. The Australian state of Victoria funded a "navigator" service ${ }^{9}$ (as did Western Australia) as a proactive approach to enable providers and consumers to understand and engage with the statutory process. New Zealand should draw on the experience with the challenges in Victoria ${ }^{3,5,6,15,24,34}$ and Canada ${ }^{18,19,35}$ to ensure access to legally available $\mathrm{AD}$ is not unduly hampered by process which does not materially enhance the safety of the system. There are procedures, forms and documents required at each step of the process. Compliance with the procedural steps and safeguards is important, but if they are disproportionate or bureaucratic, this can present barriers to access for eligible patients and deterrents for providers, without actually improving safety. $1,5,6,15,24,34$ Research from overseas suggests safeguards and processes, each of which have merit on their own, when put together can become burdensome for those involved and may undermine the stated aim of the law, to establish a lawful process for assisting eligible persons to request medical assistance to end their lives. ${ }^{3,5,6,15,18,19,24,34,35}$

The Act does not prescribe the availability of clinical ethics advice when there is a moral or ethical dilemma. Healthcare practitioners and other stakeholders will require access to a multi-disciplinary clinical ethics advisory group to assist in analysing the decision-making dilemmas that will inevitably arise. ${ }^{36,37}$

\section{Public reporting and research}

A major part of the Act's implementation is ensuring there are appropriate data 
collection processes in place, so that highquality, detailed epidemiological research can be conducted to track trends of use, to monitor safeguard adherence to protect vulnerable populations, and to ensure access is only granted to those who are eligible. Alongside quantitative data, qualitative and evaluation research is needed to capture the experiences of those involved and otherwise affected.

\section{Reporting requirements}

The number of assisted deaths, and its proportion as a percentage of all deaths, will be of considerable public interest. In addition to the Registrar's specific reporting requirements outlined in Section 27(7), the Act enables the Registrar to report on "any other matter relating to the operation of this Act that the Registrar thinks appropriate.” We advocate for the data in Figure 2 to be collected via the forms so that detailed monitoring and equity issues can be researched.

Statutory restrictions (Section 36) prohibit making some details of $\mathrm{AD}$ deaths public, including method of administration and place of death. While the purpose of this is to protect the privacy of those involved, this may prevent certain factors from being researched by non-government parties. Research about the uptake of administration methods, as well as site of death, are important aspects of reporting in other jurisdictions.

Collecting data on the reasons people are choosing $\mathrm{AD}$ is important for reporting and potentially improving health service delivery. The comprehensive end-of-life concerns list from the Oregon Death with Dignity Act Annual Reports would provide a useful comparison. Following Oregon, multiple reasons can be selected. However, in Oregon, reason(s) for seeking $\mathrm{AD}$ are recorded by physicians, not patients. ${ }^{38}$ To ensure data are accurate, this list should be incorporated into the patient's written request form as well.

The Oregon list also does not capture some reasons that New Zealand-specific research found for wanting to access AD. Some New Zealanders wish to have the option of $\mathrm{AD}$

Figure 2: Data collection recommendations for patient characteristics and assisted dying processes.

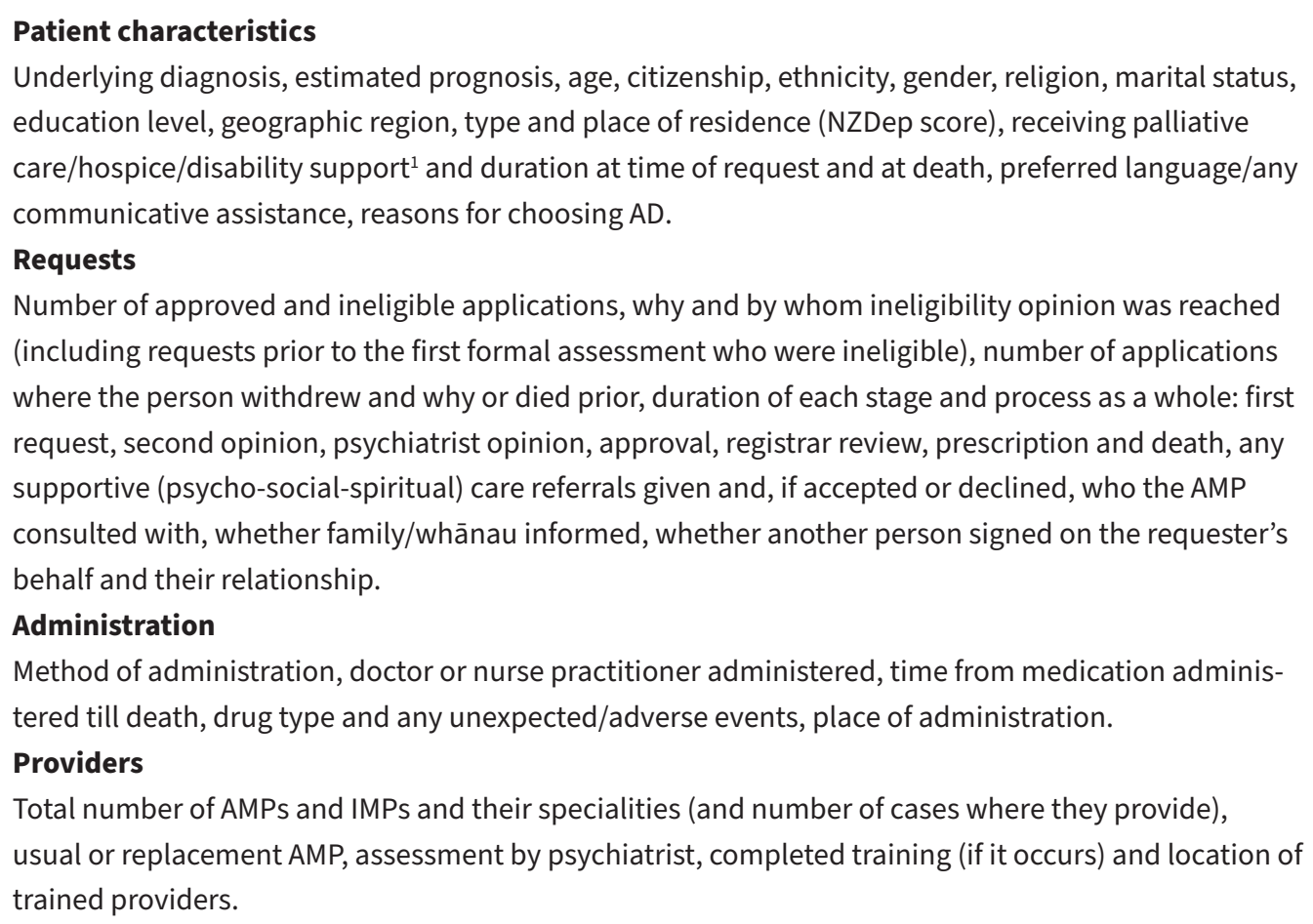

${ }^{1}$ As per Canadian reporting, disability support services could include but are not limited to assistive technologies, adaptive equipment, rehabilitation services, personal care services and disability-based income supplements. 
to hasten dying, rather than a definite wish to hasten death. ${ }^{23}$ Single item reasons may not capture holistic conceptions of hauora, including wairuatanga (spirituality); spiritual/existential beliefs are important for many at the end of life and will often be part of the decision-making processes..$^{39,40}$

\section{Experiences of accessing and providing $A D$}

In addition to these statistics, qualitative data must also be collected about how the $\mathrm{AD}$ process functions for patients, families and health professionals. These perspectives are vitally important for an optimal AD system and are also necessary to inform the legislated review after three years.

Research is needed with those who are using the $\mathrm{AD}$ system to determine how it is operating in practice and the extent to which it is achieving its policy goals. This would include research with patients and whānau, health practitioners, health administrators and $\mathrm{AD}$ regulators to understand their experience with the Act and how it has been implemented. Key questions include: How are patients and health practitioners navigating through the system? What aspects of the law and its implementation are working well and what are causing problems? Is the Act facilitating timely access to $\mathrm{AD}$ for eligible patients while safeguarding the vulnerable?

Collecting the experiences of health practitioners, both those exercising their freedom of conscience, as well as in-principle supportive providers and conscientious participants ${ }^{4,41,42}$ is also useful. When the Act is reviewed in three years, it will be important to know the support, informational and other needs of providers. One concern voiced by health practitioners is that public trust in them will change. The New Zealand Attitudes and Values study ${ }^{43}$ is well placed to monitor this and report on attitude changes over time.

Other areas of research include evaluating the quality and suitability of the palliative care offered in New Zealand and evaluating the strategies discussed that may alleviate suffering. This would be useful infor- mation to improve end-of-life care. Other future research questions include: How is decision-making shared in assisted dying processes? What learning can be gleaned from researching complaints?

Two significant gaps were identified in a systematised review of the New Zealand research on $\mathrm{AD}$ : the views of the terminally ill and those of people with disabilities. ${ }^{32}$ Since that review, research has included people considering $\mathrm{AD}$ who were approaching the end of life..$^{23,44} \mathrm{~A}$ follow-up longitudinal study of the wish to hasten death in New Zealand is necessary because research has shown it fluctuates and can co-exist with the will to live. ${ }^{45} \mathrm{New}$ Zealand would benefit from research with the diverse communities that identify as having a disability and to track their experiences over time.

\section{Conclusion}

This article has identified some of the challenges for implementation and proposed priorities for the data collection and research that must follow once $\mathrm{AD}$ becomes lawful. There is urgency in preparing for when the EoLC Act comes into force on 7 November, but this work must continue after that time as well. As was argued in relation to Victoria's recent AD law, "implementation is an ongoing process," and continuous evaluation and improvement is a necessary part of an effective AD system. ${ }^{1}$ A key part of this is research evaluating how the law is working in practice; empirical data are important for transparency and to guide improvements in practice. ${ }^{14} \mathrm{New}$ Zealand regulators will need data to know whether access is equitable, who is choosing to make use of the law, whether providers are well informed and whether the safeguards are working as intended. Monitoring the EoLC Act will provide information to the public of its operation and inform the legislated review of operation of Act within three years. Transparent reporting will foster trust in the health system. The implications of how this Act is implemented are significant for patients, whānau, health professionals and society. 


\section{Competing interests:}

Jessica Young is the recipient of a Post-Doctoral Fellowship from the Cancer Society of New Zealand. Jessica Young is an appointed member of Support and Consultation for End of Life in New Zealand (SCENZ) Group. Jessica Young and Janine Winters are members of the Ministry of Health's End of Life Choice Advisory network. Jessica Young, Colin Gavaghan and Andrew Geddis were members of the 2020 End of Life Choice Act Referendum Society/Yes for Compassion. Colin Gavaghan was an expert witness for the plaintiff in Seales v Attorney General. Ben White was engaged by the Victorian and Western Australian Governments to design and provide the legislatively mandated training for doctors involved in voluntary assisted dying in those states. Ben White also developed a model Bill for voluntary assisted dying for parliaments to consider. Ben White is a recipient of an Australian Research Council Future Fellowship (project number FT190100410: Enhancing End-of-Life Decision-Making: Optimal Regulation of Voluntary Assisted Dying) funded by the Australian Government.

\section{Author information:}

Jessica Young: Post-doctoral Research Fellow, School of Health, Faculty of Health, Victoria University of Wellington, Wellington.

Janine Winters: Senior Lecturer, Bioethics Centre, University of Otago, Dunedin.

Jeanne Snelling: Lecturer, Faculty of Law and Bioethics Centre, University of Otago, Dunedin. Ben White: Professor, Australian Centre for Health Law Research, Faculty of Business and Law, Queensland University of Technology, Australia.

Colin Gavaghan: Professor, New Zealand Law Foundation Chair in Law \& Emerging Technologies, Faculty of Law, University of Otago, Dunedin.

Andrew Geddis: Professor, Faculty of Law, University of Otago, Dunedin.

Richard Egan: Senior Lecturer, Preventive \& Social Medicine, University of Otago, Dunedin.

Corresponding author:

Dr Jessica Young, School of Health, Wellington Faculty of Health, Victoria University of Wellington, PO Box 600, Wellington 6140

jessica.young@vuw.ac.nz

URL:

www.nzma.org.nz/journal-articles/the-end-of-life-choice-act-a-proposed-implementationand-research-agenda

\section{REFERENCES}

1. White BP, Willmott L, Close E. Victoria's voluntary assisted dying law: clinical implementation as the next challenge. Med J Aust. 2019;210(5):207-209.e1. doi:10.5694/mja2.50043

2. McDougall R, Hayes B, Sellars M, et al. "This is uncharted water for all of us": Challenges anticipated by hospital clinicians when voluntary assisted dying becomes legal in Victoria. Aust Heal Rev. 2020;44(3):399-404. doi:10.1071/AH19108

3. Willmott L, White B, Ko D, Downar J, Deliens L. Restricting conversations about voluntary assisted dying: Implications for clinical practice. BMJ Support
Palliat Care. 2020;10(1):105110. doi:10.1136/ bmjspcare-2019-001887

4. Rutherford J. Conscientious participants and the ethical dimensions of physician support for legalised voluntary assisted dying. J Med Ethics. 2020;0:1-5. doi:10.1136/ medethics-2020-106702

5. Hempton C. Voluntary assisted dying in the australian state of victoria: An overview of challenges for clinical implementation. Ann Palliat Med. 2021;10(3):3575-85. doi:10.21037/apm-20-1157

6. Willmott L, White BP, Sellars M, Yates P. A qualitative study of participating doctors' perspectives and key concerns about the regulation of voluntary assisted dying in Victoria. Med J Aust. 2021;(early online):1-5. Available from: https://www.mja.com.au/ system/files/issues/215_03/ mja251123.pdf

7. Gamondi C, Fusi-Schmidhauser T, Oriani A, Payne S, Preston N. Family members' experiences of assisted dying: A systematic literature review with thematic synthesis. 2019;33(8):1091105. doi:10.1177 /0269216319857630

8. Brown J, Goodridge D, Harrison A, Kemp J, Thorpe L, Weiler R. Medical Assistance in Dying: Patients', Families', and 
Health Care Providers' Perspectives on Access and Care Delivery. J Palliat Med. 2020;23(11):1468-1477. doi:10.1089/jpm.2019.0509

9. O'Connor M, Mandel C, Mewett G, Catford DCH J, McMaugh J. Implementing voluntary assisted dying in Victoria, Australia. Int J Health Plann Manage. Published online February 16, 2021:hpm.3126. doi:10.1002/hpm.3126

10. End of Life Choice Act 2019. Published 2019. Accessed March 9, 2021. Available from: https:// www.legislation.govt. nz/act/public/2019/0067/ latest/DLM7285905.html

11. Geddis A, Jocelyn S. End of Life Choice: Coming to New Zealand by the Road Less Travelled. Aust Law J. 2021;95.

12. Ministry of Health. End of Life Choice Act. Published 2021. Accessed March 9, 2021. Available from: https://www. health.govt.nz/our-work/ regulation-health-and-disability-system/ end-life-choice-act

13. Van Wesemael Y, Cohen J, Onwuteaka-Philipsen BD, Bilsen J, Deliens L. Establishing specialized health services for professional consultation in euthanasia: Experiences in the Netherlands and Belgium. BMC Health Serv Res. 2009;9(1):220. doi:10.1186/1472-6963-9-220

14. Onwuteaka-Philipsen B, Willmott L, White BP. Regulating voluntary assisted dying in Australia: some insights from the Netherlands. Med J Aust. 2019;211(10):438-9.e1. doi:10.5694/mja2.50310

15. White BP, Willmott L, Sellars M, Yates P. Prospective oversight and approval of assisted dying cases in Victoria, Australia: a qualitative study of doctors' perspectives. BMJ Support Palliat Care. 2021;(early online). doi:10.1136/ bmjspcare-2021-002972

16. Fujioka JK, Mirza RM, Klinger CA, McDonald LP. Medical assistance in dying: implications for health systems from a scoping review of the literature. J Heal Serv Res Policy. 2019;24(3):207-16. doi:10.1177/1 355819619834962

17. O'Connor MM, Hunt RW, Gardner J, et al. Documenting the process of developing the Victorian voluntary assisted dying legislation. Aust Heal Rev. 2018;42(6):621-926. doi:10.1071/AH18172

18. Winters J, Pickering N, Jaye $\mathrm{C}$. Because it was new: Unexpected experiences of physician providers during Canada's early years of legal euthanasia/assisted dying. Health Policy (New York). Available from: https://www.sciencedirect. com/science/article/pii/ S0168851021002451?dgcid=author

19. Wiebe E, Green S, Wiebe $\mathrm{K}$. Medical assistance in dying (MAiD) in Canada: practical aspects for healthcare teams. Ann Palliat Med. 2020;9(6):38-8. doi:10.21037/apm-19-631

20. Hewitt J, White B, Del Villar K, Willmott L, Greaves LL, Meehan R. Voluntary assisted dying in Victoria: Why knowing the law matters to nurses. Nurs Ethics. Published online September 1 , 2020:096973302094445. doi:10.1177/096 9733020944457

21. White BP, Willmott L, Close E, et al. Development of Voluntary Assisted Dying Training in Victoria, Australia: A Model for Consideration.
J Palliat Care. Published online August 4, 2020:082585972094689. doi:10.1177/0825 859720946897

22. Moore B, Hempton C, Kendal E. Victoria's Voluntary Assisted Dying Act: navigating the section 8 gag clause. Med J Aust. 2020;212(2):67-8.e1. doi:10.5694/mja2.50437

23. Young J. Agency, Uncertainty and Power: Why People Consider Assisted Dying at the End of Life. Published online 2020. Accessed March 9, 2021. Available from: https:// ourarchive.otago.ac.nz/ handle/10523/10395

24. McDougall R, Pratt B. Too much safety? Safeguards and equal access in the context of voluntary assisted dying legislation. BMC Med Ethics. 2020;21(1):38. doi:10.1186/ s12910-020-00483-5

25. Pestinger M, Stiel S, Elsner $\mathrm{F}$, et al. The desire to hasten death: Using Grounded Theory for a better understanding "when perception of time tends to be a slippery slope.” Palliat Med. 2015;29(8):711-719. doi:10.1177/026921 6315577748

26. Rodríguez-Prat A, Balaguer A, Booth A, Monforte-Royo C. Understanding patients' experiences of the wish to hasten death: An updated and expanded systematic review and meta-ethnography. BMJ Open. 2017;7(9):e016659. doi:10.1136/ bmjopen-2017-016659

27. Norwood F. The Maintenance of Life : Preventing Social Death through Euthanasia Talk and End-of-Life Care : Lessons from the Netherlands. Carolina Academic Press; 2009.

28. Justice Mallon. Hospice New Zealand v Attor- 
ney-General.; 2020.

29. White BP, Willmott L, Close E, Downie J. Legislative Options to Address Institutional Objections to Voluntary Assisted Dying in Australia. UNSW Law J Forum. 2021;3:1-19. Accessed May 26, 2021. Available from: https:// www.unswlawjournal. unsw.edu.au/forum_article/ legislative-options-to-address-institutional-objections-to-voluntary-assisted-dying-in-australia/

30. Malpas PJ, Anderson A, Jacobs P, et al. 'It's not all just about the dying'. Kaumātua Māori attitudes towards physician aid-in dying: A narrative enquiry. Palliat Med. 2017;31(6):54452. doi:10.11 77/0269216316669921

31. The Hui. Māori back End of Life Choice Bill - poll | Newshub. Published 2020. Accessed March 24, 2021. Available from: https:// www.newshub.co.nz/home/ politics/2020/03/m-ori-backend-of-life-choice-bill-poll. html

32. Young J, Egan R, Walker S, Graham-DeMello A, Jackson C. The euthanasia debate: synthesising the evidence on New Zealander's attitudes. Kōtuitui New Zeal J Soc Sci Online. 2019;14(1):1-21. doi:10.108 0/1177083X.2018.1532915

33. Came H. Sites of institutional racism in public health policy making in New Zealand. Soc Sci Med. 2014;106:214220. doi:10.1016/j. socscimed.2014.01.055

34. White BP, del Villar K, Close E, Willmott L. Does the "Voluntary Assisted Dying Act” 2017 (VIC) reflect its stated policy goals? Univ N S W Law J. 2020;43(2):417-51.

35. Nuhn A, Holmes S, Kelly M, Just A, Shaw J, Wiebe E. Experiences and perspectives of people who pursued medical assistance in dying: Qualitative study in Vancouver, BC. Can Fam Physician. 2018;64(9):e380-e386.

36. Slowther A, Johnston C, Goodall J, Hope T. Development of clinical ethics committees. BMJ. 2004;328(7445):950-

952. doi:10.1136/ BMJ.328.7445.950

37. Førde R, Pedersen R. Clinical Ethics Committees in Norway: What Do They Do, and Does It Make a Difference? Cambridge Q Healthc Ethics. 2011;20(3):389-

395. doi:10.1017/ S0963180111000077

38. Oregon Health Authority. Supporting Documents Methods.; 2015. Accessed March 1, 2021. Available from: https://www.oregon. gov/oha/PH/PROVIDERPARTNERRESOURCES/ EVALUATIONRESEARCH/ DEATHWITHDIGNITYACT/ Documents/methods.pdf

39. Egan R, Macleod R, Jaye C, et al. Spiritual beliefs, practices, and needs at the end of life: Results from a New Zealand national hospice study. Palliat Support Care. 2017;15(2):22330. doi:10.1017/ S147895151600064X

40. Grant L, Murray SA, Sheikh A. Spotlight: Palliative care beyond cancer: Spiritual dimensions of dying in pluralist societies. BMJ. 2010;341(7774):659-662. doi:10.1136/bmj.c4859

41. Haining CM, Keogh LA, Gillam LH. Understanding the Reasons Behind Healthcare Providers' Conscientious Objection to Voluntary Assisted Dying in Victoria, Australia. J Bioeth Inq. Published online February 26, 2021:1-13. doi:10.1007| s11673-021-10096-1

42. Mills A, Bright K, Wortzman R, Bean S, Selby D. Medical assistance in dying and the meaning of care: Perspectives of nurses, pharmacists, and social workers. Heal An Interdiscip J Soc Study Heal Illn Med. Published online March 8, 2021:136345932199677. doi:10.1177/1363459321996 774

43. The New Zealand Attitudes and Values Study - The University of Auckland. Accessed April 7, 2021. Available from: https:// www.psych.auckland.ac.nz/ en/about/new-zealand-attitudes-and-values-study. html

44. Young J, Winters J, Jaye C, Egan R. Patients' views on end-of-life practices that hasten death: a qualitative study exploring ethical distinctions. Ann Palliat Med. 2020;9(4):7. doi:10.21037/apm-20-621

45. Nissim R, Gagliese L, Rodin $G$. The desire for hastened death in individuals with advanced cancer: A longitudinal qualitative study. Soc Sci Med. 2009;69(2):165171. doi:10.1016/j. socscimed.2009.04.021 